Journal of Exercise Science \& Physiotherapy Vol. 15 No. 1 (January to June) 2019

ISSN: 0973-2020 (Print) $\quad I_{2}$ OR Impact Factor $=6.502$

ISSN: 2454-6089 (Online)

\title{
Comparative Study of Body Mass Index and Waist Hip Ratio between Pre and Post Menopausal Women
}

\author{
Parmindejit Kaur, Anuradha Lehri, Shivani Sharma and Roopneet Kaur
}

\begin{abstract}
Aim: The aim of the study was to compare the BMI (Body Mass Index) and WHR (Waist Hip Ratio) between pre and post-menopausal women. Materials and Method: The study involved 50 females (age 45-55years) Pre-menopause and post-menopause (age 55-65 years). The anthropometric rod, weighing Scale and measuring tape were used to measure parameters i.e. body height, body weight, hip circumference, waist circumference. BMI and Waist hip ratio were also calculated from the drawn parameters. Results: The mean height and weight of the pre-menopausal and post-menopausal were $164.19 \pm 5.3 \mathrm{cms}$ and $70.40 \pm$ $6.9 \mathrm{Kg}$ and $159.21 \pm 5.90 \mathrm{~cm}$ and $67.8 \pm 6.92 \mathrm{~kg}$ respectively. The results indicated that mean height of pre-menopausal women was significantly higher than post-menopausal women. No significant difference was seen between mean BMI of females in both groups. Further, it was observed that the mean waist in post-menopausal women is higher than the premenopausal women and was statistically significant $(p<0.05)$. Conclusion: The WHR is much higher in post-menopausal women which were statistically significant. As a higher waist hip ratio is major risk factor for lifestyle diseases, were observed to be increasing with menopause, there is a need to create awareness regarding healthy lifestyle for menopausal women.

Parmindejit Kaur

Assistant Professor

Akal College of Physical College

Mastuana Sahib (Sangrur) Punjab, India

Anuradha Lehri

Assistant Professor

Department of Sports Science

Punjabi University Patiala, Punjab, India

E-mail: anu_lehri@yahoo.com

Shivani Sharma

Ph.D. Scholar

Department of Sports Science

Punjabi University Patiala, Punjab, India

E-mail: shivani_3134@yahoo.com

Roopneet Kaur

M.Sc. Student

Department of Sports Science

Punjabi University Patiala, Punjab, India

Key Words: Pre and Post
Menopause,
Awareness, Lifestyle

DOI: $10.18376 / j e s p / 2019 / v 15 / i 1 / 111316$
\end{abstract}

\section{Introduction}

The term menopause is commonly used to describe any of the changes that a woman experience either just before or after she stops menstruating, marking the end of her reproductive period due to the loss of ovarian follicular activity (Harlow et al., 2012). It is divided into two phases- Premenopause and Post-menopause. "Pre- Menopause" is a term used to mean the years leading up to the last period, when the levels of reproductive hormones are becoming more variable and lower, and the effects of hormone withdrawal are present (Harlow et al., 2012). Pre-menopause starts 


\section{Journal of Exercise Science \& Physiotherapy Vol. 15 No. 1 (January to June) 2019 ISSN: 0973-2020 (Print) I I OR Impact Factor $=6.502 \quad$ ISSN: 2454-6089 (Online)}

sometimes before the monthly cycles become noticeably irregular in timing. Post- Menopausal describes women who have not experienced any menstrual flow for a minimum of 12 months, assuming that they have a uterus and are not pregnant or lactating. Thus, post menopause is the time in a woman's life that take place after her last period or, more accurately, after the point when her ovaries become inactive (Schneider et al.,2005). Most of the women pass through menopause as a normal physiological manifestation of the aging process and they do not seek any medical intervention. Wide array of signs and symptoms are observed in women during menopause. The common symptoms associated with menopause and oestrogen deficiency include: hot Flushes, excessive perspiration, mood swings, depression, anxiety, insomnia, urinary symptoms like frequency and nocturia, vaginal dryness etc (Leidy1994). Women at menopause often experience weight gain, particularly around the abdomen. Oestrogen level may influence body fat distribution. Many women in the early menopausal years gain fat mass as their oestrogen level drop. Women of child bearing age tend to store fat in the lower body ('Pear- Shaped'), while men and postmenopausal women store fat around the abdomen ('apple- shaped'). Apart from declining oestrogen levels, other factors may contribute to weight gain after menopause include: loss of muscle tissue with age, lowered metabolism, reduced physical activity and altered habits (Lemieux et al., 1994). When looking for treatments for weight gain, it's important to begin with methods that are less obtrusive, with least of side effects. Lifestyle changes are best to begin with. Creating awareness regarding healthy lifestyle with alternative medicines best results will be produced because weight gain during menopause is associated with hormonal imbalance.

\section{Materials and Methods}

The study involved 50 women selected from the Patiala and Bhatinda, cities of Punjab. 25 women each for pre- menopausal and post-menopausal were studied. The research objective was to screen the BMI (Body Mass Index) and WHR (Waist Hip Ratio) between pre and post-menopausal women. Various equipments were used to collect data like Anthropometric Rod, weighing scale and measuring tape. Parameters were drawn from the collected data like body height, body weight, hip circumference and waist circumference. BMI and waist hip ratio were also calculated. The data recorded for various characteristics were statistically analysed. Mean, standard deviation and significant difference were calculated. Data coding and validations was also done. The collected data was analyzed by formulating the frequency distribution tables. T- test was performed to compare BMI and WHR between both the groups.

\section{Results}

Table 1. Comparison of Height, Weight, BMI, Waist and Hip Circumference between Pre and Post Menopausal Females

\begin{tabular}{|c|c|c|c|c|}
\hline \multirow{2}{*}{ Parameters } & Pre-Menopause & Post- Menopause & t value & P value \\
\cline { 2 - 5 } & Mean \pm SD n=25 & Mean \pm SD n=25 & & \\
\hline Height $(\mathrm{cm})$ & $164.9 \pm 5.3$ & $159.21 \pm 5.90$ & 3.144 & 0.0029 \\
\hline Weight $(\mathrm{Kg})$ & $70.40 \pm 6.9$ & $67.8 \pm 6.92$ & 1.328 & 0.1905 \\
\hline BMI $\left(\mathrm{Kg} / \mathrm{m}^{2}\right)$ & $26.19 \pm 3.23$ & $26.8 \pm 2.62$ & 0.7256 & 0.4716 \\
\hline Waist $(\mathrm{cm})$ & $84.12 \pm 6.65$ & $92.86 \pm 7.93$ & 4.072 & 0.0002 \\
\hline Hip $(\mathrm{cm})$ & $106.68 \pm 8.42$ & $107.39 \pm 6.66$ & 0.3311 & 0.7420 \\
\hline
\end{tabular}




\section{Journal of Exercise Science \& Physiotherapy Vol. 15 No. 1 (January to June) 2019 ISSN: 0973-2020 (Print) I I OR Impact Factor $=6.502 \quad$ ISSN: 2454-6089 (Online)}

From the above Table 1 it was observed that the mean height in pre-menopause is higher than the post menopause and the difference is statistically significant $(p<0.05)$ whereas the mean weight is also higher in pre-menopause than the post menopause and there is no significant difference in weight. The mean BMI in post menopause is higher than the post menopause and there is no statistically significant difference. Further, the mean waist and hip in post menopause is higher than the pre-menopause but statistically only mean waist has shown significance $(\mathrm{p}<0.05)$.

Table 2. Comparison of Waist Hip Ratio of Pre and Post Menopausal Women

\begin{tabular}{|l|l|l|l|l|l|}
\hline Group & Mean & Standard deviation & SEM & t value & p value \\
\hline Pre-Menopause & 0.79 & 0.05 & 0.0106 & \multirow{2}{*}{4.621} & \multirow{2}{*}{0.0001} \\
\hline Post Menopause & 0.86 & 0.06 & 0.0113 & & \\
\hline
\end{tabular}

In the above Table 2 comparison of waist hip ratio is shown between the pre and post-menopausal women. The data indicated that the mean WHR in post menopause is higher than the premenopause and the difference is statistically significant $(\mathrm{p}<0.05)$.

\section{Discussion}

In the present study, estimation of measurement of Body Mass Index and hip waist ratio was carries out in pre-menopausal and post-menopausal women. The major finding of the study was that the waist hip ratio was much higher in post-menopausal women than pre-menopausal women. Magdalena Skrzypczak (2007), states in their study that WHR which is also used as adiposity indicator, may be useful in assessment of the risk of disease or death caused by hypertension, cardiac diseases, diabetes or even cancers. However, they should not be used only in relation to obese women, because even a slight increase in visceral obesity within normal body mass limits may contribute to unfavourable changes of the women's metabolic profile, which in turn, may represent a risk of sickness to occur. Various cross sectional studies has been done among women related to postmenopausal and premenopausal. Comparison was done between the stated two categories (Ley et al.,1992) compared BMI between premenopausal and postmenopausal women. Significant differences were noted between the postmenopausal and premenopausal women. In the later studies, authors found that BMI was highest during the perimenopause period and then returned to values similar to those of premenopausal women after the onset of menopause. This finding could partially explain why some previous studies found no effect of menopause per se on BMI (Pasquali 1994). Bjorkeland et al.,(1996) found that women who became postmenopausal had greater increase in waist circumference and WHR than did women who remained premenopausal during follow-up. However, the BMI changes were identical in the two groups, suggesting that menopause is associated with significant increase in central fat accumulation, and that these changes are not accompanied by concomitant changes in BMI.

\section{Conclusion}

It was concluded that changes in BMI and WHR can be related to reduce physical activity and mental stress during postmenopausal period. During reproductive age, women are exposed possibly to more stressful conditions which release hormones like epinephrine, nor-epinephrine. Thus, collectively the increments of total body fat and central fat distribution during menopausal period is influenced by hormonal changes as well as decreased level of physical activity and mental stress during this period. Increased physical activity, awareness and proper counselling are required to overcome the lifestyle diseases among menopausal women. 


\section{Journal of Exercise Science \& Physiotherapy Vol. 15 No. 1 (January to June) 2019 \\ ISSN: 0973-2020 (Print) $\quad I_{2}$ OR Impact Factor $=6.502 \quad$ ISSN: 2454-6089 (Online)}

\section{References}

Bjourkelund C., Lissner L., Andresson S., Lapidus L., Bengtsson C. 1996. Reproductive history in relation to relative weight and fat distribution. Int Jobes.;20:213-19.

Harlow, S.D., Gass, M., Hall, J.E., Lobo, R., Maki, P., Rebar, R.W., Sherman, S., Sluss, P.M., de Villiers, T.J.2012. "Executive summary of the stages of reproductive aging workshop+10: addressing the unfinished agenda of staging reproductive aging". Fertility and Sterility. 97 (4): 398-406. Doi:10.1016/jfertnstert.2012.01.128. PMC 3340904 PMID 22341880

Leidy LE., 1994, Timing of menopause in relation to body size and weight change. Hum bioi1996;68:967-982.

Lemieux S., Prud'homme D., Tremblay A., Bouchard C., Despres J.P., 1996, Anthropometric correlates to changes in visceral adipose tissue over 7 years in women, Int Jobes.:20:618-624

Ley C.J., Lees B., Stevenson J.C., 1992. Sex- and menopause associated changes in body-fat distribution. Am J Clin Nutr.;55:950-954.

Magdalena Skrzypczak, Anita Szwed, Romana Pawlinska-Chmara, Violetta Skrzypulec.2007. Assessment of the BMI, WHR and W/Ht in pre- and post-menopausal women Anthropological Review Vol. 70, 313.

Pasquali R., Casimirri F., Morselli Labate A.M., et al., 1994. Body Weight, fat distribution and the menopausal status in women. Int Jobes.; 18:6 14-21.

Schneider, Hermann P.G., Naftolin, Frederick. (2005). Climacteric medicine where do we go? London: Taylor \& Francis. P.28 ISBN 9780203024966. Archived from an original on 10 September 2017.

Conflict of Interest: None declared 